\title{
Haemoglobin concentration following postpartum haemorrhage and the association between blood transfusion and breastfeeding: a retrospective cohort study
}

\author{
Julia Chessman ${ }^{1,3^{*}}$ (D) Jillian Patterson ${ }^{1,2}$, Tanya Nippita ${ }^{2,4}$, Bradley Drayton ${ }^{1,3}$ and Jane Ford ${ }^{1,2}$
}

\begin{abstract}
Objective: The aim of this study was to determine the association between red blood cell transfusion and breastfeeding among women who have suffered a postpartum haemorrhage at birth taking into account post-birth haemoglobin concentrations.

Results: Among 15,451 maternities with postpartum haemorrhage in New South Wales public hospitals between 2007 and 2010, 1828 (12\%) received a red cell transfusion. Among transfused women, 686 (38\%) had haemoglobin concentration pre-transfusion < $70 \mathrm{~g} / \mathrm{L}, 792$ (43\%) had 70-90 g/L, and 350 (19\%) had > 90 g/L. Rates and adjusted relative risks (aRR) for breastfeeding at hospital discharge were as follows: for women with haemoglobin concentrations $<70 \mathrm{~g} / \mathrm{L}$ following birth and received a transfusion, $78.6 \%$ were breastfeeding and the aRR of breastfeeding compared to untransfused women was 0.90 (99\% confidence interval (CI) 0.86-0.95); for women with haemoglobin concentrations $70-90 \mathrm{~g} / \mathrm{L}, 81.3 \%$ were breastfeeding, aRR 0.94 (99\% Cl 0.90-0.98); and for women with haemoglobin concentrations > $90 \mathrm{~g} / \mathrm{L}, 80.9 \%$ were breastfeeding, aRR 0.94 (99\% Cl 0.88-1.00).
\end{abstract}

Keywords: Postpartum haemorrhage, Haemoglobin concentration, Red blood cell transfusion, Breastfeeding

\section{Introduction}

Postpartum haemorrhage rates and transfusion rates following postpartum haemorrhage have been increasing in high resource settings [1-3]. In New South Wales (NSW), Australia the postpartum haemorrhage rate has recently been estimated at $8.3 \%$ and postpartum haemorrhage with transfusion at $1.2 \%$ of births [3].

In the postpartum anaemic woman without ongoing bleeding, the decision to transfuse may not be straightforward. Clinicians must weigh the benefits to energy levels against the risks of transfusion such as bloodborne infections, transfusion reactions and immunologic effects [4]. Pregnant and recently pregnant women are generally healthy and can tolerate some anaemia, however there

\footnotetext{
*Correspondence: julia.chessman@health.nsw.gov.au

${ }^{1}$ Clinical and Population Perinatal Health Research, Kolling Institute, Northern Sydney Local Health District, St Leonards, NSW, Australia Full list of author information is available at the end of the article
}

are other factors to consider including caring for a new baby.

Breastfeeding is an important aspect of early infant care, with benefits for both infant and maternal health [5]. Studies have shown that postpartum anaemia is associated with insufficient milk supply and early breastfeeding cessation [6, 7]. Anecdotally, some clinicians believe that transfusion may increase the likelihood of breastfeeding in postpartum anaemic woman [8].

An analysis of breastfeeding rates at discharge in women with postpartum haemorrhage in NSW hospitals found that transfusion was associated with a lower rate of breastfeeding [9]. After adjustment for clinical and demographic factors, Drayton et al. found the rate of any breastmilk feeding at discharge to be 0.94 (99\% confidence interval (CI) 0.92, 0.95) in transfused vs nontransfused women. At the time, data were not available to indicate the severity of the haemorrhage and the extent 
to which this influenced the findings. Data on haemoglobin concentration pre- and post-transfusion have since become available for a subgroup of the NSW birthing population.

The aim of this study is to explore the association between red blood cell transfusion and breastfeeding among women who have suffered a postpartum haemorrhage taking into account haemoglobin concentrations pre-transfusion.

\section{Main text \\ Methods}

The study population included maternities where the mother suffered a postpartum haemorrhage (defined as blood loss of at least $500 \mathrm{~mL}$ post-vaginal birth and at least $750 \mathrm{~mL}$ post-caesarean birth) following a singleton birth of at least 37 weeks gestation where the mother and baby were alive at hospital discharge. The cohort was further restricted to births that occurred in a NSW public hospital that submitted blood transfusion data to the NSW Clinical Excellence Commission (CEC) Blood Watch program between January 2007 and December 2010.

Data were drawn from the NSW Perinatal Data Collection (PDC), the NSW Admitted Patient Data Collection (APDC) and the CEC Blood Watch program database. These datasets were probabilistically linked by the Centre for Health Record Linkage (CHeReL) [10]. The PDC is a statutory data collection of all births in NSW of at least 20 weeks gestation or $400 \mathrm{~g}$ birth weight and contains information on the pregnancy, labour and delivery. The APDC is a census of all patient admissions in NSW hospitals and contains up to 50 diagnoses and procedures coded from the medical record. The CEC Blood Watch program database contains information on red blood cell transfusion and pathology results in NSW public hospitals between July 2006 and December 2010. Hospital participation in the program was staggered over time. In the months when a hospital was participating in the program, information on each blood pack issued and the results of haemoglobin pathology tests were submitted to the CEC Blood Watch program. About half of all births in NSW between July 2006 and December 2010 occurred in a public hospital that was submitting data to the CEC Blood Watch program. This subset is representative of the NSW public hospital maternity population, but marginally higher risk compared to the NSW maternity population overall [11].

The study exposure was red blood cell transfusion following postpartum haemorrhage and the outcome was any breastfeeding at hospital discharge. Maternities were excluded from the analysis if the mother was admitted to intensive care or transfused with other blood products (platelets, coagulation factors or serum). These factors suggest that the mother suffered a severe haemorrhage and were excluded to make the transfused and nontransfused groups more comparable. Maternities where the mother was transfused during the birth admission but prior to the baby's date of birth, or transfused but did not have a haemoglobin measure on or up to 2 days prior to transfusion, were also excluded.

Postpartum haemorrhage and transfusion of red blood cells or other blood products were identified using diagnosis and procedure codes in hospital records. Ascertainment of these conditions and procedures is high in hospital data [12]. If a mother did not have a transfusion procedure code in hospital data but was issued blood during their hospital admission (according to CEC Blood Watch data); they were also classified as transfused. The blood pack issue date and the haemoglobin order date in CEC Blood Watch data were taken as the date of transfusion and the date of haemoglobin measure respectively. Baby feeding status at discharge-breastfeeding, expressed breast milk and/or infant formula-was obtained from birth records. Mothers were considered to be exclusively breastfeeding if either or both of the first two options were selected, and partially breastfeeding if infant formula was selected in addition to either or both of the first two options. Exclusive and partial breastfeeding were combined into a single category, 'any breastfeeding', for analysis.

Poisson regression models with sandwich error estimation [13] were used to explore the relationship between transfusion and breastfeeding among maternities with postpartum haemorrhage. The analysis was stratified by haemoglobin concentration prior to transfusion-less than $70 \mathrm{~g} / \mathrm{L}, 70-90 \mathrm{~g} / \mathrm{L}$ and greater than $90 \mathrm{~g} / \mathrm{L}$ as per haemoglobin ranges used in maternity guidelines [14]. We used the lowest haemoglobin measure on or up to 2 days prior to transfusion to stratify results. Each haemoglobin-transfusion group was compared to the entire non-transfused group. Descriptive statistics on haemoglobin measures after transfusion but before hospital discharge were produced for each haemoglobin-transfusion group. Haemoglobin measures were not available for the non-transfused group.

Factors included in modelling to control for confounding were: maternal age, country of birth, marital status, parity, hypertension, diabetes, smoking during pregnancy, public/private patient status, analgesia for labour and delivery, mode of delivery, gestational age, large for gestational age ( $>90$ th percentile of birth weight, given gestational age), small for gestational age $(<10$ th percentile of birth weight, given gestational age) [15], resuscitation procedures, Apgar score at 5 min less than seven, transfer of baby, admission to special care nursery or 
neonatal intensive care unit, maternal morbidity [16] (a composite measure of morbidity but in this case excluding transfusions and procedures limiting blood flow to the uterus), maternal hospital classification [17], year of birth, and length of the birth admission from date of birth. These variables have high validity $[12,18]$. Records with missing covariate information were excluded from the regression analysis. Purposeful selection [19] was followed with variables significant at the 0.01 level or variables that when excluded caused a greater than $10 \%$ change in coefficients retained in the model.

Ethics approval was obtained from the NSW Population and Health Services Research Ethics Committee. The analyses were performed in SAS 9.3.

\section{Results}

There were 16,504 maternities with postpartum haemorrhage in our study population. Four percent $(n=636)$ of maternities were excluded based on an indication of a severe postpartum haemorrhage (intensive care admission or other blood products transfused). A further 19 maternities were excluded for a transfusion prior to the baby date of birth. Among the 2226 (14\%) maternities involving red blood cell transfusion, 398 (18\%) were excluded because they did not have a haemoglobin measure on or up to 2 days prior to transfusion. The final cohort of 15,451 maternities with postpartum haemorrhage included 1828 transfused mothers (1691 identified in APDC, additional 137 identified in CEC Blood Watch data) and 13,623 non-transfused mothers. Covariate information was missing for 126 maternities and they were excluded from regression analysis. Among transfused mothers, 686 (38\%) had haemoglobin concentration pre-transfusion $<70 \mathrm{~g} / \mathrm{L}, 792(43 \%)$ had $70-90 \mathrm{~g} / \mathrm{L}$ and $350(19 \%)$ had $>90 \mathrm{~g} / \mathrm{L}$.

A higher percentage of the transfused mothers were primiparous compared to the non-transfused mothers (55\% vs $49 \%$ ) (Table 1). Among the transfused mothers, primiparous women were over-represented in the lowest haemoglobin group. Maternal morbidity [16] was about six times higher in transfused mothers compared to nontransfused mothers (6\% vs $1 \%)$. Among the transfused mothers, the rate of maternal morbidity was slightly higher in the haemoglobin group $>90 \mathrm{~g} / \mathrm{L}$ compared to the other two groups. The babies of transfused mothers were more likely to be admitted to a special care nursery or a neonatal intensive care unit compared to the babies of non-transfused mothers ( $20 \%$ vs $14 \%$ ).

Among the 1828 transfused mothers, 1714 (94\%) had one or more haemoglobin measures after transfusion and before discharge. The median haemoglobin concentration before and after transfusion for each haemoglobin group was 65 and $91 \mathrm{~g} / \mathrm{L}, 76$ and $94 \mathrm{~g} / \mathrm{L}$ and 107 and
$98 \mathrm{~g} / \mathrm{L}$ (Fig. 1). There was a significant increasing trend between haemoglobin group pre-transfusion and haemoglobin concentration post-transfusion $(\mathrm{p}<0.0001)$. For those mothers with multiple haemoglobin measures after transfusion, the highest value was used to calculate these medians.

Eighty percent of transfused mothers were breastfeeding at discharge compared to $87 \%$ of non-transfused mothers. Among the transfused mothers, the percentage breastfeeding across the three pre-transfusion haemoglobin groups - < 70 g/L, 70-90 g/L, >90 g/L-were 79\%, $81 \%$ and $81 \%$ respectively (Table 1 ).

The adjusted relative risk for any breastfeeding for transfused women compared to non-transfused women was 0.90 (99\% CI 0.86-0.95) for the haemoglobin $<70 \mathrm{~g} / \mathrm{L}$ group, 0.94 (99\% CI $0.90-0.98$ ) for the haemoglobin 70-90 g/L group; and 0.94 (99\% CI 0.88-1.00) for the haemoglobin $>90 \mathrm{~g} / \mathrm{L}$ group (Table 2).

\section{Discussion}

We examined the association between red blood cell transfusion and breastfeeding in women with postpartum haemorrhage by differing postnatal haemoglobin concentrations. We found that red blood cell transfusion was associated with a reduced rate of breastfeeding and this was a consistent finding irrespective of haemoglobin concentration pre-transfusion. The median haemoglobin concentration post-transfusion was greater than $90 \mathrm{~g} / \mathrm{L}$ for each haemoglobin-transfusion group, which suggests that severe persisting anaemia was not contributing to the reduced breastfeeding rates in the transfused groups.

The findings of this study align with a population-based analysis of breastfeeding rates at discharge in women with postpartum haemorrhage in NSW hospitals, which found that transfusion was associated with a lower rate of breastfeeding [9].

Among the strengths of our study is the study population selection. By defining the study cohort as women with postpartum haemorrhage, we were able to assess the impact of transfusion among a comparable group of women at risk of transfusion. Furthermore, by restricting the cohort to less severe postpartum haemorrhage and term infants, confounding of breastfeeding rates by haemorrhage severity and infant complications was reduced.

\section{Limitations}

This study was limited by a lack of data on haemoglobin concentrations in women not transfused. Each haemoglobin-transfusion group was compared to the entire non-transfused group so breastfeeding at discharge may have been confounded by differences in haemorrhage severity or haemoglobin level. That is, the reason 
Table 1 Demographic and clinical characteristics of maternities with postpartum haemorrhage by transfusion and haemoglobin concentration prior to transfusion

\begin{tabular}{|c|c|c|c|c|c|c|c|c|}
\hline & \multicolumn{6}{|c|}{ Transfusion } & \multirow{2}{*}{\multicolumn{2}{|c|}{ No transfusion }} \\
\hline & \multicolumn{2}{|c|}{ Haemoglobin $<70 \mathrm{~g} / \mathrm{L}$} & \multicolumn{2}{|c|}{ Haemoglobin $70-90 \mathrm{~g} / \mathrm{L}$} & \multicolumn{2}{|c|}{ Haemoglobin $>90 \mathrm{~g} / \mathrm{L}$} & & \\
\hline & $\mathrm{n}$ & $\mathrm{col}^{\mathrm{a}}$ & $n$ & $\mathrm{col}^{\mathrm{a}}$ & $\bar{n}$ & col$^{a}{ }^{a}$ & $n$ & $\mathrm{col}^{\mathrm{a}} \mathrm{a}^{\mathrm{a}}$ \\
\hline Maternities & 686 & & 792 & & 350 & & 13,623 & \\
\hline \multicolumn{9}{|l|}{ Maternal age } \\
\hline 19 and under & 29 & 4.2 & 28 & 3.5 & 8 & 2.3 & 285 & 2.1 \\
\hline $20-34$ & 550 & 80.2 & 629 & 79.4 & 266 & 76.0 & 10,715 & 78.7 \\
\hline 35 and over & 107 & 15.6 & 135 & 17.0 & 76 & 21.7 & 2622 & 19.2 \\
\hline \multicolumn{9}{|l|}{ Country of birth } \\
\hline Australia & 394 & 57.4 & 526 & 66.4 & 223 & 63.7 & 7987 & 58.6 \\
\hline Asia & 165 & 24.1 & 146 & 18.4 & 61 & 17.4 & 2718 & 20.0 \\
\hline Other and not stated & 127 & 18.5 & 120 & 15.2 & 66 & 18.9 & 2918 & 21.4 \\
\hline \multicolumn{9}{|l|}{ Parity } \\
\hline Primipara & 424 & 61.8 & 427 & 53.9 & 159 & 45.4 & 6611 & 48.5 \\
\hline $1-2$ previous births & 203 & 29.6 & 290 & 36.6 & 157 & 44.9 & 5696 & 41.8 \\
\hline $3+$ previous births & 58 & 8.5 & 73 & 9.2 & 34 & 9.7 & 1303 & 9.6 \\
\hline Hypertension & 94 & 13.7 & 92 & 11.6 & 54 & 15.4 & 1191 & 8.7 \\
\hline Diabetes & 47 & 6.9 & 46 & 5.8 & 30 & 8.6 & 1093 & 8.0 \\
\hline Smoked during pregnancy & 98 & 14.3 & 118 & 14.9 & 47 & 13.4 & 1624 & 11.9 \\
\hline Private patient & 69 & 10.1 & 96 & 12.1 & 42 & 12.0 & 1472 & 10.8 \\
\hline Analgesia_-spinal/epidural & 320 & 46.6 & 352 & 44.4 & 139 & 39.7 & 5497 & 40.4 \\
\hline Analgesia_-general anaesthetic & 139 & 20.3 & 158 & 19.9 & 83 & 23.7 & 942 & 6.9 \\
\hline Analgesia_opioid & 170 & 24.8 & 192 & 24.2 & 70 & 20.0 & 2967 & 21.8 \\
\hline \multicolumn{9}{|l|}{ Delivery mode } \\
\hline Vaginal (including breech) & 386 & 56.3 & 434 & 54.8 & 207 & 59.1 & 8694 & 63.8 \\
\hline Instrumental birth & 189 & 27.6 & 183 & 23.1 & 62 & 17.7 & 2376 & 17.4 \\
\hline Caesarean_labour & 76 & 11.1 & 121 & 15.3 & 49 & 14.0 & 1574 & 11.6 \\
\hline Caesarean—no labour & 35 & 5.1 & 53 & 6.7 & 32 & 9.1 & 957 & 7.0 \\
\hline Maternal morbidity & 39 & 5.7 & 45 & 5.7 & 26 & 7.4 & 117 & 0.9 \\
\hline Placenta praevia/accreta & 29 & 4.2 & 41 & 5.2 & 32 & 9.1 & 222 & 1.6 \\
\hline \multicolumn{9}{|l|}{ Estimated gestational age (weeks) } \\
\hline $37-38$ & 148 & 21.6 & 149 & 18.8 & 86 & 24.6 & 2567 & 18.8 \\
\hline $39-40$ & 364 & 53.1 & 439 & 55.4 & 177 & 50.6 & 7795 & 57.2 \\
\hline $41+$ & 174 & 25.4 & 204 & 25.8 & 87 & 24.9 & 3261 & 23.9 \\
\hline Large for gestational age & 96 & 14.0 & 131 & 16.5 & 54 & 15.4 & 2012 & 14.8 \\
\hline Small for gestational age & 42 & 6.1 & 47 & 5.9 & 25 & 7.1 & 963 & 7.1 \\
\hline Resuscitated & 67 & 9.8 & 81 & 10.2 & 43 & 12.3 & 1102 & 8.1 \\
\hline Apgar score $<7$ at 5 min & 13 & 1.9 & 15 & 1.9 & 9 & 2.6 & 200 & 1.5 \\
\hline Transfer of baby & 9 & 1.3 & 13 & 1.6 & 10 & 2.9 & 311 & 2.3 \\
\hline Admitted to SCN or NICU & 125 & 18.2 & 153 & 19.3 & 80 & 22.9 & 1898 & 13.9 \\
\hline \multicolumn{9}{|l|}{ Breastfeeding at discharge } \\
\hline No breastfeeding & 147 & 21.4 & 148 & 18.7 & 67 & 19.1 & 1761 & 12.9 \\
\hline Exclusive & 447 & 65.2 & 562 & 71.0 & 235 & 67.1 & 10,740 & 78.8 \\
\hline Partial & 92 & 13.4 & 82 & 10.4 & 48 & 13.7 & 1122 & 8.2 \\
\hline Any & 539 & 78.6 & 644 & 81.3 & 283 & 80.9 & 11,862 & 87.1 \\
\hline \multicolumn{9}{|l|}{ Hospital group } \\
\hline NICU or CPAP & 473 & 69.0 & 510 & 64.4 & 183 & 52.3 & 9404 & 69.0 \\
\hline Urban & 112 & 16.3 & 117 & 14.8 & 56 & 16.0 & 2165 & 15.9 \\
\hline Regional & 101 & 14.7 & 165 & 20.8 & 111 & 31.7 & 2054 & 15.1 \\
\hline
\end{tabular}

NICU neonatal intensive care unit, CPAP continuous positive airway pressure; $S C N$ special care nursery

a Percentages may not sum to $100 \%$ due to missing values 


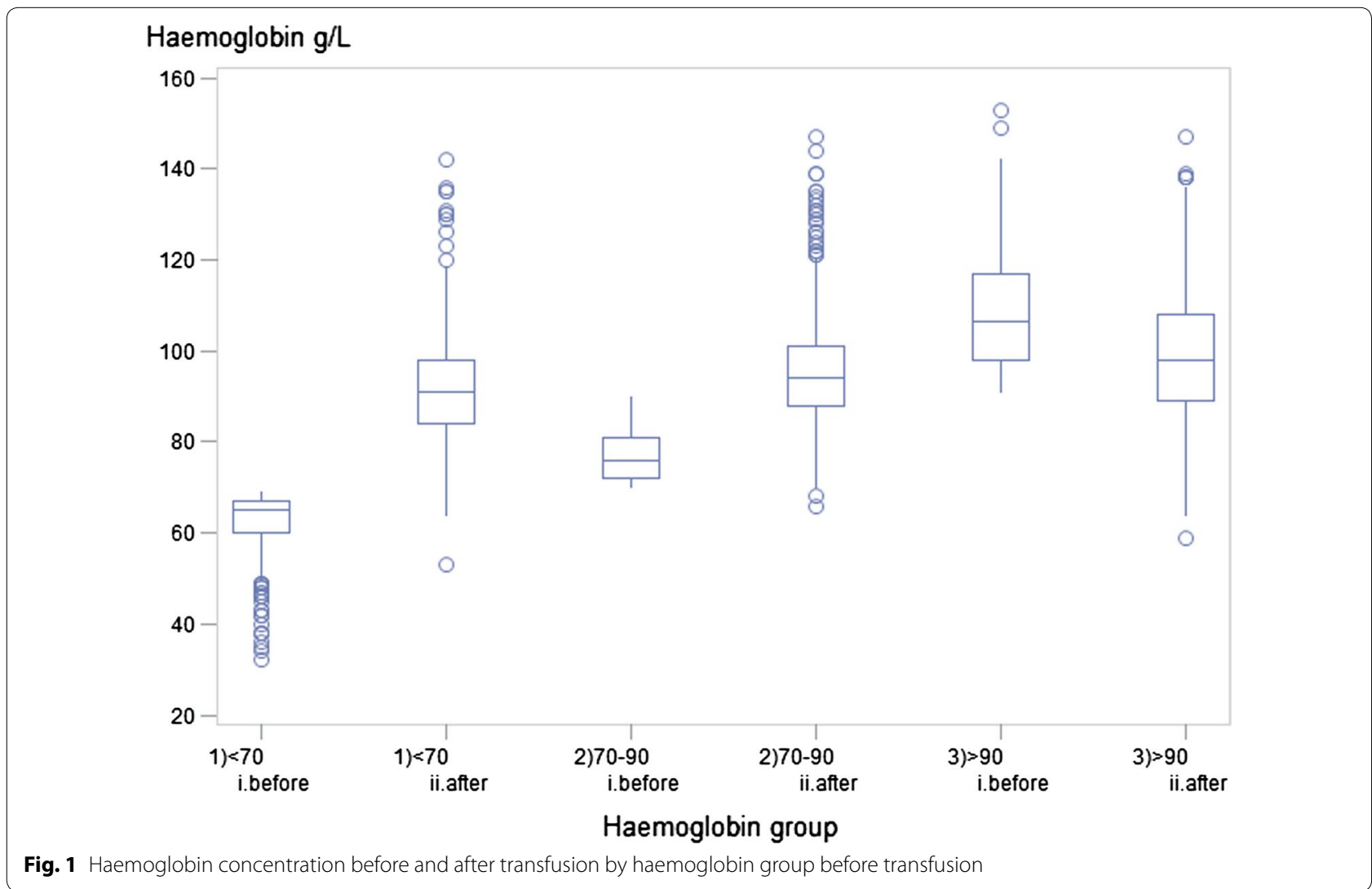

Table 2 Unadjusted and adjusted relative risks (URR; aRR) for transfusion with any breastfeeding by haemoglobin concentration prior to transfusion

\begin{tabular}{llcccc}
\hline Variable & Value & $\mathbf{n}$ & Any breastfeeding & uRR (99\% Cl) & aRR $\left.\mathbf{~}^{\mathbf{9 9}} \% \mathbf{C l}\right)$ \\
\hline Transfusion & Haemoglobin $<70 \mathrm{~g} / \mathrm{L}$ and transfusion & 686 & $539(79 \%)$ & $0.90(0.86-0.95)$ & $0.90(0.86-0.95)$ \\
& Haemoglobin $70-90 \mathrm{~g} / \mathrm{L}$ and transfusion & 792 & $644(81 \%)$ & $0.93(0.89-0.98)$ & $0.94(0.90-0.98)$ \\
& Haemoglobin $>90 \mathrm{~g} / \mathrm{L}$ and transfusion & 350 & $283(81 \%)$ & $0.93(0.87-0.99)$ & $0.94(0.88-1.00)$ \\
& No transfusion (reference) & 13,623 & $11,862(87 \%)$ & 1.00 & 1.00 \\
\hline
\end{tabular}

a Adjusted for all variables in Table 1 except for private obstetrician, placenta praevia/accreta, large and small for gestational age and resuscitation

women were transfused may also be the reason they were less likely to breastfeed than women who weren't transfused. However, even the highest haemoglobintransfusion group, which is likely to have similar if not higher haemoglobin levels compared to the non-transfused group, had a reduced breastfeeding rate. Other study limitations include lack of available information on ongoing breastfeeding post-discharge and amount of blood lost or transfused. Given that some women are discharged from hospital within $48 \mathrm{~h}$ and before breastfeeding is established (and this is more likely to occur among the untransfused women), we may be underestimating the extent of the effect of transfusion on reduced breastfeeding. Finally, the decision for intrapartum transfusion may have been made based on point of care haemoglobin testing which can be less accurate than laboratory testing [20] and no information on duration of bleeding was available so it is difficult to draw conclusions about the appropriateness of transfusion from these data.

\section{Abbreviations}

APDC: Admitted Patient Data Collection; aRR: adjusted relative risk; CEC: Clinical Excellence Commission; CHeReL: Centre for Health Record Linkage; Cl: confidence interval; NSW: New South Wales; PDC: Perinatal Data Collection; URR: unadjusted relative risk. 


\section{Authors' contributions}

JF and JP conceived the study. JC performed the analysis. JP and BD assisted in the analysis. JC, TN, JP, BD and JF were involved in interpretation, drafting the manuscript and critically revising the content. All authors read and approved the final manuscript.

\section{Author details \\ ${ }^{1}$ Clinical and Population Perinatal Health Research, Kolling Institute, Northern Sydney Local Health District, St Leonards, NSW, Australia. ${ }^{2}$ The University of Sydney Northern Clinical School, St Leonards, NSW, Australia. ${ }^{3}$ NSW Biostatistics Training Program, NSW Ministry of Health, North Sydney, Australia. ${ }^{4}$ Department of Obstetrics and Gynaecology, Royal North Shore Hospital, St Leonards, NSW, Australia.}

\section{Acknowledgements}

The authors thank the NSW Ministry of Health for access to the population health data, the NSW Clinical Excellence Commission for access to the blood transfusion data and the NSW Centre for Health Record Linkage for linking the data sets. This work was completed while JC and BD were employed as trainees on the NSW Biostatistics Training Program funded by the NSW Ministry of Health. They undertook this work whilst based at the Kolling Institute.

\section{Competing interests}

The authors declare that they have no competing interests.

\section{Availability of data}

The custodians of the population health data and the blood transfusion data used in this study are the NSW Ministry of Health and the NSW Clinical Excellence Commission respectively.

\section{Consent for publication}

Not applicable.

\section{Ethics approval and consent to participate}

Ethics approval was obtained from the NSW Population and Health Services Research Ethics Committee, Approval Number: 2012/02/369, 13/8/2016.

\section{Funding}

This work was supported by a National Health and Medical Research Council Partnership Grant (\#APP1094822). JF is supported by an Australian Research Council Future Fellowship (\#FT120100069).

\section{Publisher's Note}

Springer Nature remains neutral with regard to jurisdictional claims in published maps and institutional affiliations.

Received: 9 Auqust 2018 Accepted: 27 September 2018

Published online: 01 October 2018

\section{References}

1. Knight M, Callaghan WM, Berg C, Alexander S, Bouvier-Colle MH, Ford $J \mathrm{~B}$, et al. Trends in postpartum hemorrhage in high resource countries: a review and recommendations from the International Postpartum Hemorrhage Collaborative Group. BMC Pregnancy Childbirth. 2009;9:55.
2. Mehrabadi A, Hutcheon JA, Lee L, Liston RM, Joseph KS. Trends in postpartum hemorrhage from 2000 to 2009: a population-based study. BMC Pregnancy Childbirth. 2012;12:108.

3. Ford JB, Patterson JA, Seeho SKM, Roberts CL. Trends and outcomes of postpartum haemorrhage, 2003-2011. BMC Pregnancy and Childbirth. 2015; 15(1):334

4. Jansen AJ, Rhenen DJ, Steegers EA, Duvekot JJ. Postpartum hemorrhage and transfusion of blood and blood components. Obstet Gynecol Surv. 2005:60(10):663-71.

5. Gartner LM, Morton J, Lawrence RA, Naylor AJ, O'Hare D, Schanler RJ, et al. Breastfeeding and the use of human milk. Pediatrics. 2005;115(2):496-506.

6. Henly S, Anderson C, Avery M, Hills-Bonuyk S, Potter S, Duckett L. Anemia and insufficient milk in first-time mothers. Birth. 1995:22(2):87-91.

7. Rioux FM, Savoie N, Allard J. Is there a link between postpartum anemia and discontinuation of breastfeeding? Can J Diet Pract Res. 2006;67(2):72-6.

8. Mayson E, Shand AW, Ford JB. Single-unit transfusions in the obstetric setting: a qualitative study. Transfusion (Paris). 2016;56:1716-22.

9. Drayton B, Patterson JA, Nippita T, Ford JB. Red blood cell transfusion after postpartum haemorrhage and breast milk feeding at discharge: a population based study. Aust N Z J Obstet Gynaecol. 2016;56:591-8.

10. Bentley JP, Ford JB, Taylor LK, Irvine KA, Roberts CL. Investigating linkage rates among probabilistically linked birth and hospitalization records. BMC Med Res Methodol. 2012:12:149.

11. Patterson JA, Ford J. Linkage of four administrative datasets to examine blood transfusion in pregnancy. Camperdown: University of Sydney; 2015

12. Lain SJ, Roberts CL, Hadfield RM, Bell JC, Morris JM. How accurate is the reporting of obstetric haemorrhage in hospital discharge data? A validation study. Aust N Z J Obstet Gynaecol. 2008:48(5):481-4.

13. Zou G. A modified poisson regression approach to prospective studies with binary data. Am J Epidemiol. 2004;159(7):702-6.

14. National Blood Authority. Patient Blood Management Guideline: module 5-obstetrics and maternity. Canberra: National Blood Authority; 2015.

15. Dobbins TA, Sullivan EA, Roberts CL, Simpson JM. Australian national birthweight percentiles by sex and gestational age, 1998-2007. Med J Aust. 2012:197(5):291-4.

16. Roberts CL, Cameron CA, Bell JC, Algert CS, Morris JM. Measuring maternal morbidity in routinely collected health data: development and validation of a maternal morbidity outcome indicator. Med Care. 2008:46(8):786-94.

17. Falster MO, Roberts CL, Ford J, Morris J, Kinnear A, Nicholl M. Development of a maternity hospital classification for use in perinatal research. $\mathrm{N}$ SW Public Health Bull. 2012;23(1-2):12-6.

18. Lain SJ, Hadfield RM, Raynes-Greenow CH, Ford JB, Mealing NM, Algert CS, et al. Quality of data in perinatal population health databases: a systematic review. Med Care. 2012;50:e7-20.

19. Hosmer D, Lemeshow S. Applied logistic regression. 2nd ed. New York: Wiley; 2000

20. Skelton VA, Wijayasinghe N, Sharafudeen S, Sange A, Parry NS, Junghans C. Evaluation of point-of-care haemoglobin measuring devices: a comparison of Radical-7 pulse co-oximetry, HemoCue((R)) and laboratory haemoglobin measurements in obstetric patients* . Anaesthesia. 2013;68(1):40-5. 